\title{
Sliding Mode Observer-based Actuator Fault Reconstruction for a Continuous Reactor
}

\author{
Mohammad-Hossien Khooban ${ }^{1, *}$, Emad Mohammadi ${ }^{2}$ \\ ${ }^{1}$ Department of Computer Engineering and IT, Shiraz University of Technology, Iran \\ ${ }^{2}$ Department of Electrical Engineering, Islamic Azad University of Iran, Garmsar Branch, Garmsar 91775-1111, Iran
}

Copyright $\bigcirc 2016$ by authors, all rights reserved. Authors agree that this article remains permanently open access under the terms of the Creative Commons Attribution License 4.0 International License

\begin{abstract}
The problem of fault detecting subject to external disturbances has been a topic of considerable interest. In this paper, a sliding mode observer for fault detection and isolation is applied to a continuous reactor. Additionally, a general review has been done on dynamic model of continuous reactor along with detailed study of the mathematical model of these kinds of systems. Then, sliding mode observer is investigated with detailed comment. In order to isolate and estimate the possible actuator faults a bank of Sliding Mode Observer (SMO) is designed. Also a simple canonical form for sliding mode observer is presented. A design procedure is described and linear simulation results are presented to demonstrate the approach.
\end{abstract}

Keywords Sliding Mode Observer, Fault Detection and Isolation, Continuous Reactor, Canonical Form for Sliding Mode Observer, CSTR Reactors

\section{Introduction}

In some systems like CSTR reactors and other complex systems, some sensors cannot be placed in desirable location. There is not any reason for that, expect fault detection and isolation. Fault in sensors or actuators can cause process degradation even in the chemical plants. For instance lower product quality. Addition Fault cause fatal accidents (e.g. temperature run-away). Furthermore, for a group of variables no sensor exists. Concentrations and moles belong to this group. So the accurately monitoring process variables and interpreting their variations increases quickly with the increase in the range of instrumentation. For operating a process in normal situation used a set of tools and methods, called supervision. Two main activities of supervision are real Fault Detection and Isolation (FDI) and Fault Tolerant Control (FTC). The parts of the supervision scheme are shown in Fig. 1. FDI and FTC achieve safe operation of the system in the presence of faults. This paper is focused on FDI, for FTC can refer to [1].

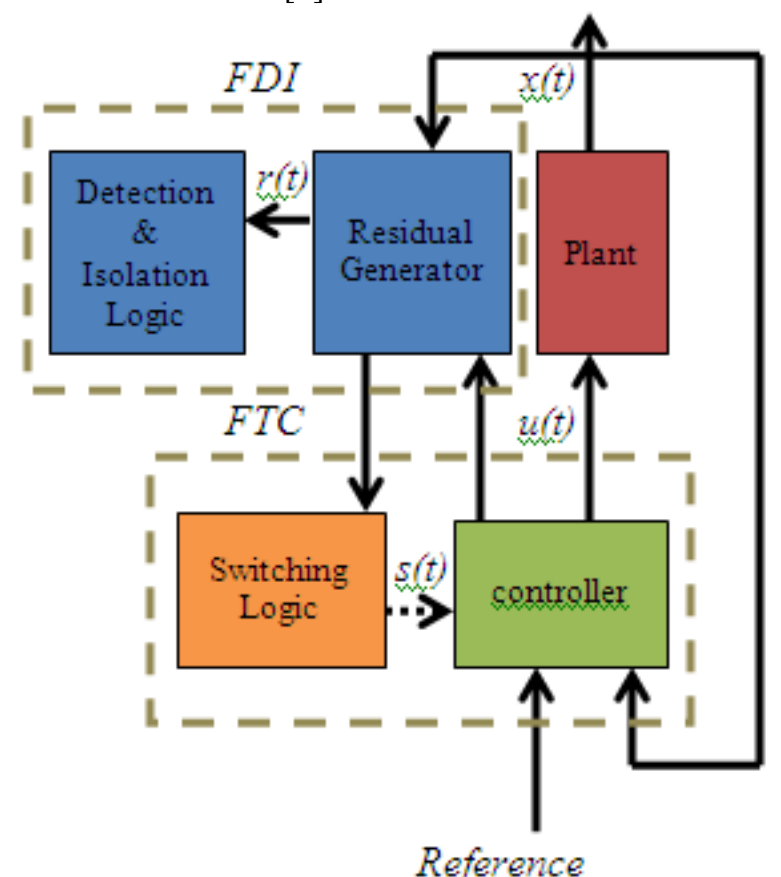

Figure 1. FDI and FTC in a system

Researchers used existing approaches such the classic ones to develop their performance for new complex systems [2-4], or tried to find new approaches for performing fault diagnosis [5], [6], [7] and [8]. Applications of fault diagnosis approaches techniques to batch chemical processes are usually challenging, these depend on intrinsically unsteady operating conditions and their nonlinear dynamics. Generally, complete state is usually not available [9]. This is also honest about parameters measurements in a chemical plant (i.e. products composition). These approaches can be based on historical data or a mathematical model [10-13].

For Model-based methods we need to detect and isolate faults (i.e. the presence of one or more faults can be recognized, the faulty components are determined). In fact, the comparison between the measurements of variables set 
characterizing the behavior of the monitored system and the corresponding estimates predicted via the mathematical model of system can be useful to consist of model-based methods. The deviations between measured and estimated process variables provide a group of residuals, sensitive to the occurrence of faults. Observer-based schemes that are kind of model-based analytical redundancy approaches, is successfully adopted in a variety of application fields [14, 16]. Diagnostic observer is operated in parallel to the process to compute estimated process variables to be compared to their measured values. Some of approaches are based on Kalman and/or Luenberger observer. Their applications to reactors diagnosis are designed by resorting to linearized models of reactor $[17,18]$.

Control problem of uncertain systems that have been exposed to an external perturbation has been an enabled field of study during the last decade. The majority of systems that we facing them in real terms are exposed to different uncertainties like nonlinearities, actuator faults, variations in parameters, and etc. In majority of proposed control strategies is assumed that all state variables are existing; this assumption is not always correct in real terms, therefore the state vector should be appraised for using in the control rules. The basic objective of a fault identification plan is to produce a warning when faults happen. Among research activities performed in this field can cited to Kalman filter [19], adaptive observers [20], high gain observers [21], sliding mode observers (SMO) [22-24], etc. See [25] to perform comparing.

A certain situation amongst observer based methods is taken by sliding mode observers. Largely, the sliding mode observer takes advantage from discontinuous control operation to move the observer fault direction toward a certain hyper-plane in the fault space, and then the direction is preserved to slide on this so long as the origin of the state space is attained. Basically, Observer generated the signals which are used to discover data associated with the fault. Specifically, 'remaining generation' statements, using as linear observers, have been extensively applied. In this method, difference among output of the system and output of the observer is calculated by a scaling matrix to create known as remaining. The remaining will equal zero if fault does not occur in the process, however will reply specifically once a special fault happens [26-27].

Utkin designed an ordinary observer, just with discontinuous part getting fed back along a suitable gain [28]. Walcott and Zak [23, 29] designed an observer where the output fault getting fed back linearly and applied a Lyapunov method to demonstrate the sustainability. Edwards and Spurgeon $[31,24]$ suggested a canonical form for designing of sliding mode observer depending on special circumstances associated with the output and input distribution matrices, and as well as the invariable zeros of the system. Their procedure expressed in $[30,24]$ used both linear and nonlinear output error injection. A procedure for calculation the gain as related with the linear output error injection part is provided. The solution is obvious, however does not utilize all grades of freedom. Tan and Edwards [32] offered another canonical form based on an adequate status according to linear matrix inequality (LMI). The paper attempts to utilize the freedom in [30] for sectional pole attribution. However, they did not determine the most appropriate place for eigenvalues in the favorable district. Their procedure is partly complicated, although their procedure is obvious [33].

In this study, a simple SMO is proposed for a special of class of linear systems in the presence of faults/unknown inputs. All the parametric uncertainties/disturbances present in the system are modeled in the form of unknown inputs/faults. The unknown input can be a combination of un-measurable or unmeasured disturbances, unknown control actions, or un-modeled system dynamics. The novelty of this study lies in the choice of robust terms to deal with faults/unknown inputs. The methods of the researches use all the output information to deal with unknown inputs, and so require the reduced order system itself to be stable in the sliding model. Moreover, the robust terms are applied to 'reconstruct' all the faults/unknown inputs from the sliding mode. Finally, a Continuous Reactor system example is given to illustrate the efficiency of the proposed approach.

\section{Study about Continuous Reactor}

\subsection{Description of the Continuous Reactor}

The continuous reactor with heat exchange is used in manufacturing plants for many process operations such as fermentation, chemical synthesis, polymerization, crystallization ...etc.

Reaction vessel, a jacket vessel, an entry and exit feeding pipes, a coolant and products, valves, a stirring system and a heat exchange surface make an important group of the systems. In a continuous reactor many process depend on this group (e.g. the process to be supervised). However, the reaction takes place within the reactor but jacket is fitted to the reactor vessel by using an external heated transfer coil wrapped around the vessel surface. A system alike washer machine keep in good condition the mixture among the reactants and products with a good homogeneous degree of physical and chemical properties.

Function of the location does not consist of concentration and temperature variables. They just represent average values for all the reactor volume.

Some irreversible and exothermic reactions happen in the reactor vessel [15], the oxidation of sodium thiosulfate

By hydrogen peroxide is given by:

$\mathrm{Na}_{2} \mathrm{~S}_{2} \mathrm{O}_{3}+2 \mathrm{H}_{2} \mathrm{O}_{2} \rightarrow \frac{1}{2} \mathrm{Na}_{2} \mathrm{~S}_{2} \mathrm{O}_{6}+\frac{1}{2} \mathrm{Na}_{2} \mathrm{SO}_{4}+2 \mathrm{H}_{2} \mathrm{O}$

The kinetic law is written as following:

$$
r_{A}=-(k+\Delta k) \exp \left(-\frac{E_{a} \Delta E_{a}}{R T_{r}}\right) P_{A} P_{B}
$$


Where $P_{A}$ and $P_{B}$ are concentrations of components $\mathrm{A}$ and $\mathrm{B}$ ( $\mathrm{B}$ is the $\mathrm{H}_{2} \mathrm{O}_{2}$ and $\mathrm{A}$ is the $N a_{2} \mathrm{~S}_{2} \mathrm{O}_{3}$ ), $\mathrm{R}$ is the perfect gas constant, $E_{a}$ is the activation energy, $\mathrm{k}$ is the pre-exponential factor, $T_{r}$ is the reactor temperature and $\Delta$ represent uncertainty.

Energy balances and A mole balance for species A and the cooling jacket result in the following nonlinear process model with $\left(P_{A}=P_{B}\right)$ :

$$
\begin{gathered}
\dot{P}_{A}=\frac{F_{r}}{V}\left(P_{\text {Ain }}-P_{A}\right)-2 k(t) P_{A}^{2} \\
\dot{T}_{r}=\frac{F_{r}}{V}\left(T_{\text {in }}-T_{r}\right)+ \\
2 \frac{\left(-\Delta H_{r}\right)+\Delta\left(-\Delta H_{r}\right)}{\rho P_{p}} k(t) P_{A}^{2} \\
-\frac{U A+\Delta U A}{\rho P_{p}}\left(T_{r}-T_{j}\right) \\
\dot{T}_{j}=\frac{F_{\omega}}{V_{\omega}}\left(T_{j i n}-T_{j}\right)+\frac{U A+\Delta U a}{\rho_{\omega} P_{p \omega} V_{\omega}\left(T_{r}-T_{j}\right)}
\end{gathered}
$$

Where the new parameter $\left(T_{j}\right)$ is the cooling jacket temperature. The three equations represent of three states. State vector can be defined as:

$$
x(t)=\left[\begin{array}{l}
x_{1} \\
x_{2} \\
x_{3}
\end{array}\right]=\left[\begin{array}{l}
P_{A} \\
T_{r} \\
T_{j}
\end{array}\right]
$$

And the initial state vector is:

$$
x(0)=\left[\begin{array}{l}
x_{1}(0) \\
x_{2}(0) \\
x_{3}(0)
\end{array}\right]=\left[\begin{array}{l}
P_{\text {Ain }} \\
T_{\text {rin }} \\
T_{j i n}
\end{array}\right]
$$

\subsection{Model Linearization}

For $\quad P_{A}=0.0192076 \mathrm{~mol} / l, T_{r}=384.005 \mathrm{~K} \quad$ and $T_{j}=271.272 \mathrm{~K}$, the nominal nonlinear system is stable and chosen as a normal operating point. The linear model around the chosen steady state is:

$$
\begin{gathered}
\left\{\begin{array}{c}
\dot{x}=A x+B u \\
y=C x
\end{array}\right. \\
x=\left[\begin{array}{l}
\Delta P_{A} \\
\Delta T_{r} \\
\Delta T_{j}
\end{array}\right] ; y=\left[\begin{array}{l}
\Delta T_{r} \\
\Delta T_{j}
\end{array}\right] ; \\
A=\left[\begin{array}{ccc}
-125.8815 & -0.0747 & 0 \\
1.7711 e+004 & 6.5538 & 2.8571 \\
0 & 28.5714 & -31.5714
\end{array}\right] ; \\
B=\left[\begin{array}{l}
0 \\
0 \\
3
\end{array}\right] ; C=\left[\begin{array}{ccc}
0 & 1 & 0 \\
0 & 0 & 1
\end{array}\right] ; u=T_{\text {jin }}
\end{gathered}
$$$$
\text { with fault is obtained as follows: }
$$$$
\left\{\begin{array}{c}
\dot{x}=A x+B u+F f_{a} \\
y=C x
\end{array}\right.
$$

Where $f_{s}$ is sensor fault, $f_{a}$ is actuator fault, $F=\left[\begin{array}{l}0 \\ 0 \\ 3\end{array}\right]$ is fault matrix in state expression.

\section{FDI Using Sliding Mode Observer}

Notice the following dynamical system

$$
\begin{gathered}
\dot{x}(t)=A x(t)+B u(t)+D f_{i}(t) \\
y(t)=C x(t)+f_{0}(t)
\end{gathered}
$$

where $A \in R^{n \times n}, B \in R^{n \times m}, C \in R^{p \times n}, D \in R^{n \times q}$ with $q \leq p \leq n, A \in R^{n}$ is the state vector, $u \in R^{m}$ is the input vector and $y \in R^{p}$ is the output vector. Also $f_{i}(t)$ and $f_{0}(t)$ show the actuator and sensor faults, respectively. The matrices $\mathrm{C}$ and $\mathrm{D}$ are supposed to be full rank. Here, $u(t)$ and $y(t)$ are accessible.

Suppose the observer of the form:

$$
\begin{gathered}
\dot{\hat{x}}(t)=A \hat{x}(t)+B u(t)-G_{l} e_{y}(t)+G_{n} v \\
\hat{y}(t)=C \hat{x}(t)
\end{gathered}
$$

where $G_{l}, G_{n} \in R^{n \times p}$ are proper gain matrices. The discontinuous vector $v$ is presented by:

$$
v=\left\{\begin{array}{c}
-\rho\left\|D_{2}\right\| \frac{P_{2} e_{y}(t)}{\left\|P_{2} e_{y}(t)\right\|} e_{y} \neq 0 \\
0 \text { otherwise }
\end{array}\right.
$$

Where $e_{y}(t)=\hat{y}(t)-y(t) \quad$ and $\quad P_{2} \in R^{p \times p} \quad$ is symmetric positive definite. The definitions of the matrices $P_{2}$ and $D_{2}$ and the scalar can $\rho(t)$ are presented in the later part. The discontinuous term is designed to drive the $D_{2}$ trajectories of the observer in a way that the state prediction error vector is forced into and as a result stays on a surface in the error space.

Now consider the dynamical system offered in (5) and (6) and suppose that:

$$
* \operatorname{rank}(C D)=q
$$

* Invariable zeros of (A, D, C) must lie in the open LHP

First, suppose the case that $f_{0}(t)=0$. It can be demonstrated that under these hypotheses, there exists a resemblance transformation as $T$ (The result expressed in $[30,35]$ confirms the existence of a nonsingular transform matrix to have this structure, and two ways to gain it is presented in the Appendix) such a way that the system will be appear in the following form

$$
\begin{gathered}
\dot{x}_{1}(t)=A_{11} x_{1}(t)+A_{12} y(t)+B_{1} u(t) \\
\dot{y}(t)=A_{21} x_{1}(t)+A_{22} y(t)+B_{2} u(t)+D_{2} f_{i}(t)
\end{gathered}
$$

Where, $x_{1} \in R^{n-p}$ and the matrix $A_{11}$ has stable eigenvalues [35]. The above transformation is applied to gain the following form of observer (7):

$$
\begin{gathered}
\hat{\dot{x}}_{1}(t)=A_{11} \hat{x}_{1}(t)+A_{12} \hat{y}(t)+B_{1} u(t)-A_{12} e_{y}(t) \\
\hat{y}(t)=A_{21} \widehat{x_{1}}(t)+A_{22} \hat{y}(t)+B_{2} u(t)- \\
-\left(A_{22}-M\right) e_{y}(t)+v
\end{gathered}
$$

where $\mathrm{M}$ is a stable design matrix that must be specified by designer. Also, $P_{2}$ is a Lyapunov Matrix for $\mathrm{M}$ and the scalar $\rho$ is selected in such that

$$
\left\|f_{i}(t)\right\|<\rho(t)
$$




$$
\begin{gathered}
\dot{e}_{1}(t)=A_{11} e_{1}(t) \\
e_{y}(t)=A_{21} e_{1}(t)+M e_{y}(t)+v-D_{2} f_{i}(t)
\end{gathered}
$$

Where

$$
\begin{array}{r}
e_{1}(t)=\hat{\dot{x}}_{1}(t)-\hat{x}_{1}(t) \\
e_{y}(t)=\hat{y}(t)-y(t)
\end{array}
$$

It is demonstrated in [35] that the nonlinear error system in (12) is stable and a sliding motion takes place forcing $e_{y}(t)=0$ in limited time. The dynamical system in (12) may so be considered as an observer for the system in (5) and (6). It follows that if

$$
G_{l}=T^{-1}\left[\begin{array}{c}
A_{12} \\
A_{22}-M
\end{array}\right], G_{n}=T^{-1}\left[\begin{array}{c}
0 \\
I_{P}
\end{array}\right]
$$

then the observer presented in (12) can be written in the basis of the main coordinates in the form of (7).

It is demonstrated that, offered a sliding motion can be achieved, the state of the system can be restored and also, estimates of $\mathrm{fj}(\mathrm{t})$ and $\mathrm{f},(\mathrm{t})$ can be calculated as:

$$
f_{i}(t) \approx-\rho(t)\left\|D_{2}\right\|\left(D_{2}^{T} D_{2}\right)^{-1} D_{2}^{T} \frac{P_{2} e_{y}(t)}{\left\|P_{2} e_{y}(t)\right\|+\delta}
$$

And

$$
f_{i}(t) \approx-\left(A_{22}-A_{21} A_{11}^{-1} A_{12}\right)^{-1} \frac{P_{2} e_{y}(t)}{\left\|P_{2} e_{y}(t)\right\|+\delta}
$$

where $\delta$ is a small positive scalar and $f_{0}(t)$ is supposed to be a slowly changing fault [35].

\section{Simulation Results}

Simulation 1: Until now, many controllers have been proposed for industrial systems [36-91]. However, none of them cannot show a good performance when faults accrue in these systems. So, in this section by choosing a chemical system, we try to show the superiority of our proposed method than conventional ones. Consider the continuous reactor equations (6). This results in the triple system below

$$
\begin{gathered}
\dot{x}=\left[\begin{array}{ccc}
-125.8815 & -0.0747 & 0 \\
1.7711 e+004 & 6.5538 & 2.8571 \\
0 & 28.5714 & -31.5714
\end{array}\right] x+\left[\begin{array}{l}
0 \\
0 \\
3
\end{array}\right] u \\
y=\left[\begin{array}{lll}
0 & 1 & 0 \\
0 & 0 & 1
\end{array}\right] x
\end{gathered}
$$

With supposed the fault distribution matrix $\mathrm{D}=\mathrm{B}$. Using an algorithm like that suggested in [1] it can be demonstrated that in the canonical form of the system will be appeared in the following form:

$$
\begin{gathered}
A=\left[\begin{array}{ccc}
-125.8815 & -0.0747 & 0 \\
1.7711 e+004 & 6.5538 & 2.8571 \\
0 & 28.5714 & -31.5714
\end{array}\right] \\
D=\left[\begin{array}{l}
0 \\
0 \\
3
\end{array}\right]
\end{gathered}
$$

$$
C=\left[\begin{array}{lll}
0 & 1 & 0 \\
0 & 0 & 1
\end{array}\right]
$$

Using the suggested procedure:

$$
\begin{aligned}
G_{l} & =\left[\begin{array}{cc}
22.4197 & 1.6205 \\
2.6723 & 1.8571 \\
27.5714 & -32.5714
\end{array}\right] \\
G_{n} & =\left[\begin{array}{cc}
-4.8614 & 0 \\
3.0000 & 0 \\
0 & 3.0000
\end{array}\right]
\end{aligned}
$$

In this specific design the scalar function $\rho=35$ and design of the observer is perfect. General scheme of the designed Sliding Mode Observers is shown in Figs. 2, 3.

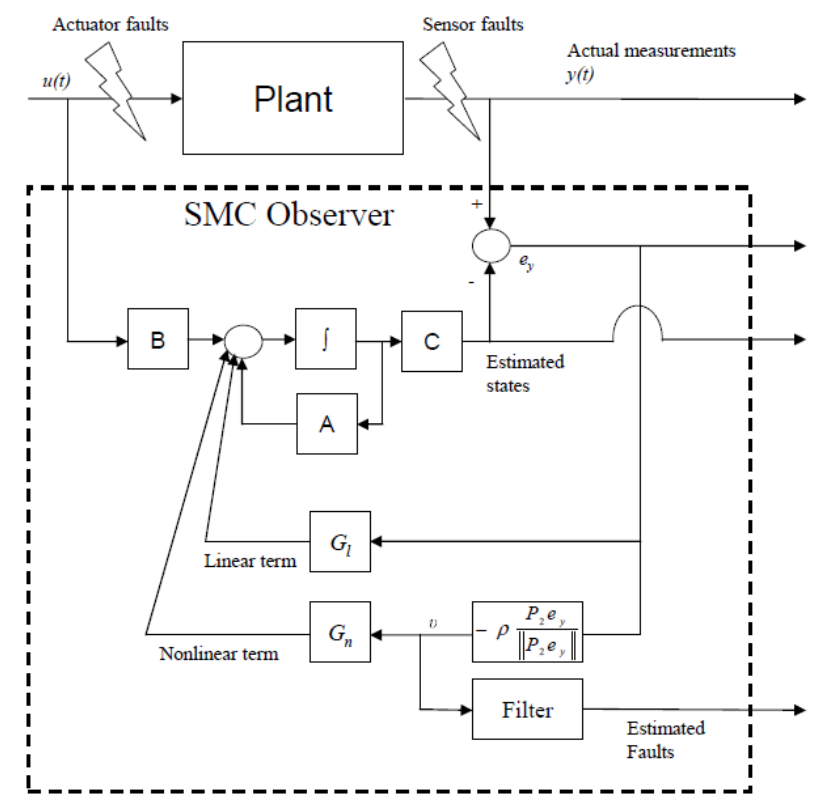

Figure 2. SMO with fault estimation

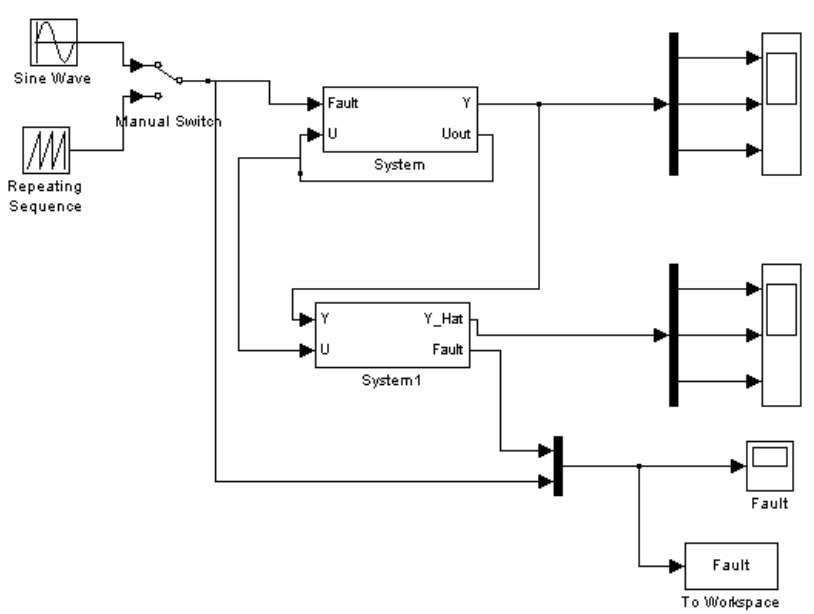

Figure 3. Simulation design in Matlab

Simulation results for fault estimation and determination are shown in Figs. 4, 5. You can see that the robust term was able to track the fault occurred, the reconstructed fault from the Sliding mode. 


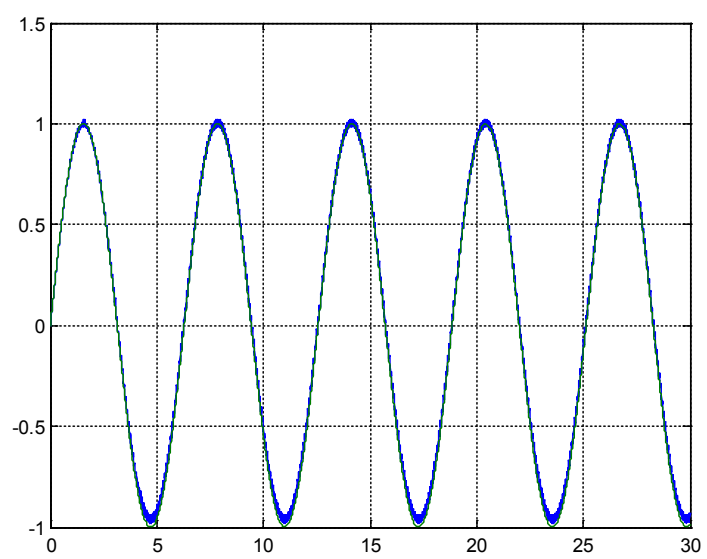

Figure 4. The reconstructed Fault Signal for Sin Wave

Simulation 2 [89]: In this stage, a fault estimator based on the proposed sliding mode observer of Edwards et al.(1999) is designed for an HIRM aircraft system [89]. Then the performance of the proposed method is compared with that of the sliding mode observer presented by Edwards et al.(1999) to show the superiority of the proposed method. It should be noted that the design parameters of the proposed method are the same as those in the first stage of simulation. It can be concluded from Fig. 5 that the proposed observer has estimated the fault efficiently. But the sliding mode observer of Yan et al. (2007) shows chattering and is not highly accurate. By changing the fault, as shown in Fig. 6 to verify the robustness of the suggested procedure, we selected $6 \sin (0.6 \pi \mathrm{t})-3 \cos (0.35 \pi \mathrm{t})$ as a fault signal. It can be observed that the performance of the proposed method is still acceptable. Although the sliding mode observer of Edwards et al.(1999) does not have chattering, it has a high estimation error making its implementation problematic.

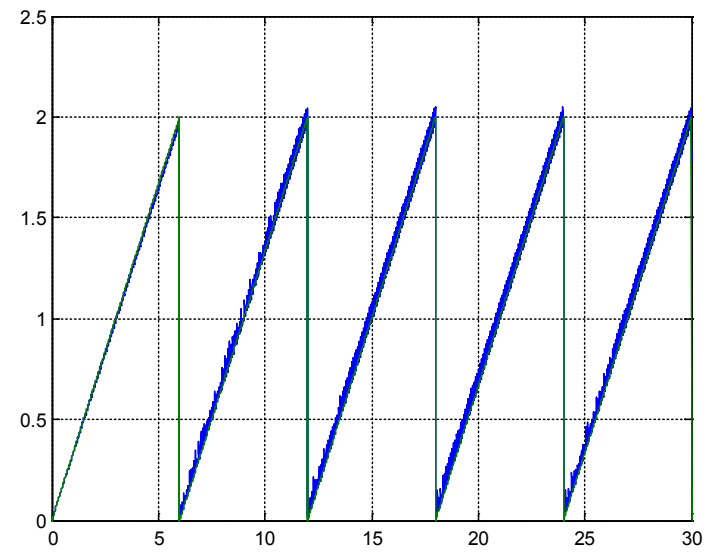

Figure 5. The reconstructed Fault Signal for Repeating Sequence Wave

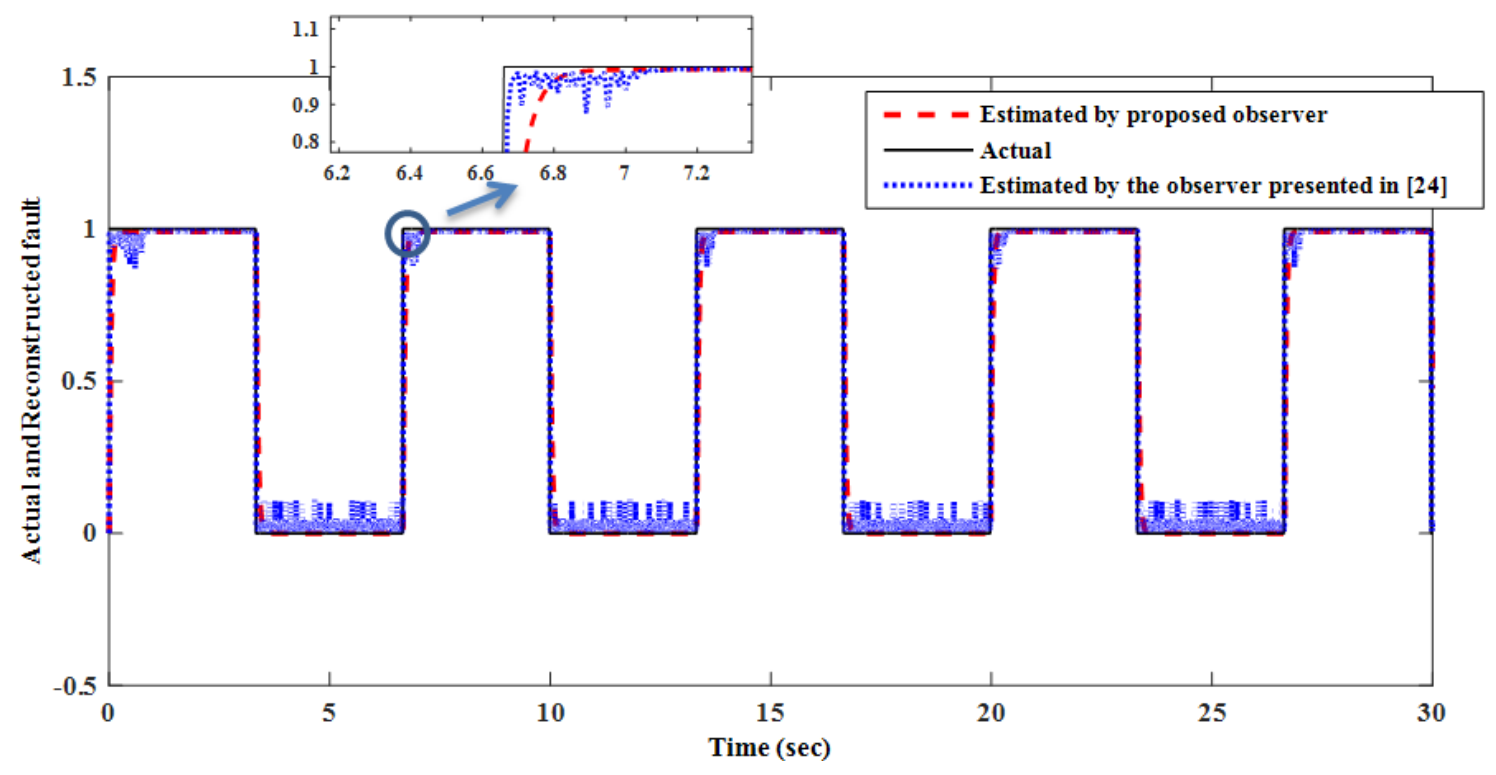

Figure 5. A fault and its estimation (first example) 


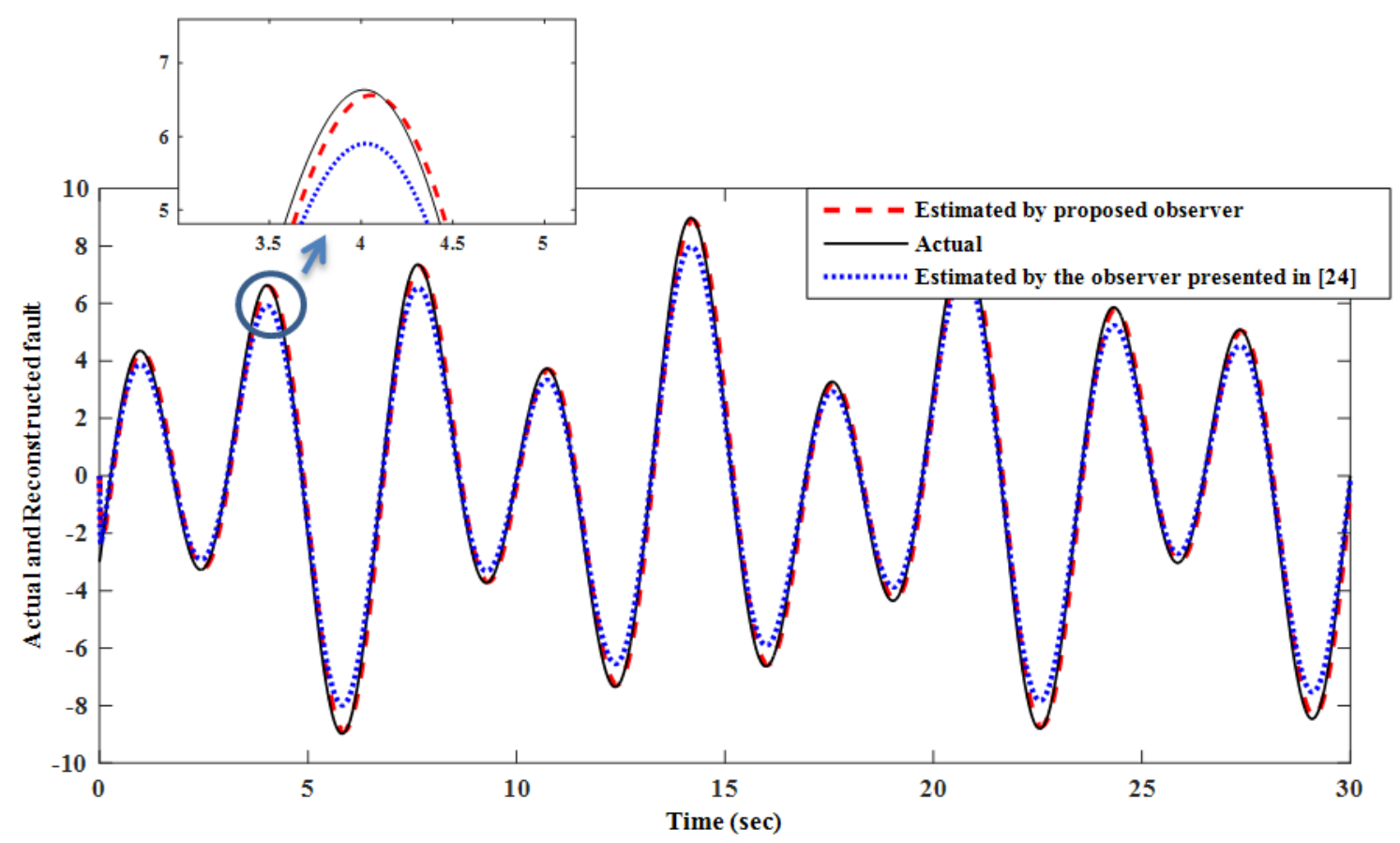

Figure 6. A fault and its estimation (second example)

\section{Conclusions}

This paper demonstrates how Sliding Mode Observers can be used to detect, estimate and isolate of the faults in actuators. In addition, the proposed method is simple and is of a relatively lower complexity compared to existing methods. Robust terms are designed in a way that faults can be reconstructed directly from the sliding surfaces. Our proposed method does not need a nonlinear transformation. The stability of the reduced-order error system in the sliding mode is established. Moreover, conditions for the existence of a sliding mode linear functional observer are given. Then is demonstrated once the existing circumstances are satisfactory, how to discover parameters of the observer. The proposed FDI (Fault Detection and Isolation) design is easy to implement and can be applied to a reasonably wide class of systems. The numerical example for a continuous reactor illustrates that this approach is effective and easy to implement.

\section{Appendix}

Let state description of the system (1), (2) with $m=p$ is

$$
\begin{array}{r}
\dot{x}(t)=A x(t)+B u(t)(\text { A. } 1) \\
y(t)=C x(t)(\text { A. } 2) \\
C_{1}=C T_{1}=\left[\begin{array}{ll}
0 & I_{p}
\end{array}\right], T_{1}^{-1}=\left[\begin{array}{cc}
I_{n-p} & 0 \\
C
\end{array}\right]
\end{array}
$$

Then

$$
B_{1}=T_{1}^{-1} B=T_{1}^{-1}\left[\begin{array}{l}
B_{01} \\
B_{02}
\end{array}\right]=\left[\begin{array}{l}
B_{01} \\
C B
\end{array}\right]=\left[\begin{array}{l}
B_{11} \\
B_{12}
\end{array}\right]
$$

If $C B=B_{12}$ is a regular matrix (in opposite case the pseudoinvers os $B_{12}$ is possible to use), then the second transform matrix $T_{2}^{-1}$ can be defined as follows

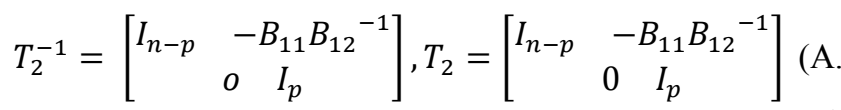

These results in

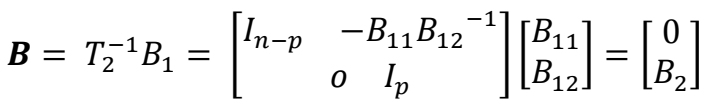

Where

$$
B_{11}=B_{01}, B_{2}=B_{12}=C B
$$

and

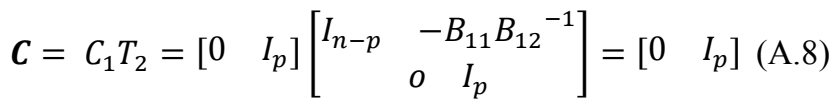

Finally, with $T_{\text {con }}^{-1}=T_{2}^{-1} T_{1}^{-1}$ it yields

$$
\boldsymbol{A}=T_{\text {con }}^{-1} A T_{\text {con }}
$$

Thus, (A.6), (A.8) and (A.9) represent the system canonical model.

\section{Note}

The structure of $T_{1}^{-1}$ is not unique and others can be obtained by permutations of the first $n-p$ rows in the structure defined in (A.3) (Please check example in [35]). 


\section{REFERENCES}

[1] M. Blanke., Michel Kinnaert, Jan Lunze, and Marcel Staroswiecki, "Diagnosis and Fault-Tolerant Control", Springer Verlag, 2006.

[2] Y. Chetouani, "Fault detection by using the innovation signal: application to an exothermic reaction", Chemical Engineering and Processing, 43, 1579-1585, 2004.

[3] V. Venkatasubramanian, R. Rengaswamy, K. Yin, and S.N Kavuri, "A review of process fault detection and diagnosis Part I: Quantitative model-based methods, Computers and Chemical Engineering”, 27, 293-311, 2003.

[4] V. Venkatasubramanian, "Prognostic and diagnostic monitoring of complex systems for product lifecycle management: Challenges and opportunities", Computers and Chemical Engineering, 29, 1253-1263, 2005

[5] A.K. Samantaray, K. Medjaher, B. Ould Bouamama, M. Staroswiecki and G. Dauphin-Tanguy, "Diagnostic bond graphs for online fault detection and isolation", Simulation Modelling Practice and Theory, 14, 237-262, 2006.

[6] R. El Harabi, B. Ould Bouamama, M. El Koni Ben Gayed, M.N. Abelkrim, "Pseudo Bond Graph for Fault Detection and Isolation of an Industrial Chemical Reactor, Part I: Bond Graph Modeling", 9th International Conference on Bond Graph Modeling and Simulation, 11 - 16 Avril 2010, Orlando, Florida, pp. 180-189. ISBN 978-1-61738-209-3, 2010a.

[7] R. El Harabi, B. Ould Bouamama, M. El Koni Ben Gayed, M.N. Abelkrim, "Pseudo Bond Graph for Fault Detection and Isolation of an Industrial Chemical Reactor, Part I: Bond Graph Modeling", 9th International Conference on Bond Graph Modeling and Simulation, 11 - 16 Avril 2010, Orlando, Florida, pp. 190-197. ISBN 978-1-61738- 209-3, 2010 b.

[8] O. Levenspiel, "Chemical reaction engineering”, New York: John Wiley \& Sons, 121-123, 1999.

[9] L.J. De Miguela and L.F Blàzquez, "Fuzzy logic-based decision-making for fault diagnosis in a DC motor", Engineering Applications of Artificial Intelligence, 18, 423-450, 2005.

[10] Evsukoffa and S. Gentil, "Recurrent neuro-fuzzy system for fault detection and isolation in nuclear reactors", Advanced Engineering Informatics, 19, 55-66, 2005.

[11] F. Caccavale, F. Pierri, M. Lamarino, and V. Tufano, "An integrated approach to fault diagnosis for a class of chemical batch processes", Journal of process control, 19:827-841, 2009.

[12] P.M. Frank, "Fault diagnosis in dynamic systems using analytical and knowledge based redundancy-a survey and some new results", Automatica, 26, 459-474, 1990.

[13] R.J. Patton and J. Chen, "Observer-Based Fault Detection and Isolation: Robustness and Applications", Control Eng. Practice, 5, 671-682, 1997.

[14] O.A.Z. Sotomayor, and D. Odloak, "Observer-based fault diagnosis in chemical plants", Chemical Engineering Journal, 112, 93-108, 2005

[15] S. Rajaraman, J. Hahn, and M.S. Mannan, "Sensor fault diagnosis for nonlinear processes with parametric uncertainties", Journal of Hazardous Materials, 130, 1-8, 2006.
[16] Z. Han, W. Li and S.L. Shah, "Fault detection and isolation in the presence of process uncertainties", Control Engineering Practice, 13, 587-599, 2005.

[17] Hsoumi, R. El Harabi, S. Bel Hadj Ali and M.N Abdelkrim, "Diagnosis of a Continuous Stirred Tank Reactor Using Kalman Filter", International Conference on Computational Intelligence, Modelling and Simulation, (cssim), pp:153-158, 2009.

[18] Favache and D. Dochain, "Thermodynamics and chemical systems stability: The CSTR case study revisited", Journal of Process Control, 19, 371-379, 2009.

[19] R.E. Kalman, "On a New Approach to Filtering and Prediction Problems", ASME J.Basic Engineering, Vol. 24, pp. 705-718, 1976.

[20] M. Gevers and G. Bastin, "A Stable Adaptive Observer for a Class of Nonlinear Second-Order Systems, in Analysis an Optimization of Systems", Bensoussan and Lions, Eds. New York Springer-Verlag, pp. 143-155, 1986

[21] J. P. Hammouri and H. Othman, "A Simple Observer for Nonlinear Systems", Applications to Bioreactors, IEEE Trans, on Automatic Control, vol. 37, no. 6, pp. 875-880, 1992.

[22] V.I. Utkin, "Sliding Modes in Control Optimization", Berlin: Springer Verlag, 1992.

[23] B. L. Walcott and S. H. Zak, "Observation of dynamical systems in the presence of bounded nonlinearities/uncertainties", Proc. of the 25th Conference on Decision and Control, pp. 961-966, 1986.

[24] C. Edwards and S. K. Spurgeon, "On the development of discontinuous observers", Int. J. Control, vol. 59, no. 5, pp. 1211-1229, 1994.

[25] M.-W. L. Thein and E. A. Misawa, "Comparison of the Sliding Observer to Several State Estimators Using a Rotational Inverted Pendulum", Proc. of the 34th Conference on Decision and Control, New Orleans, pp. 3385-3390, 1995.

[26] P.M Frank, "Fault diagnosis in dynamic systems using analytical and knowledge based redundancy - a survey and some new results", Automatica, 26:459-474, 1990

[27] J.F Magni and P. Mouyon, "On residual generation by observer and parity space approaches", IEEE Trans, Aut, Control, 39(2):447, 1994.

[28] C. Edwards and S. K. Spurgeon, "Sliding mode control", Taylor \& Francis Ltd., 1998.

[29] B. L. Walcott and S. H. Zak, "Combined Observer Controller synthesis for Uncertain Dynamical Systems with Applications", IEEE Transactions on Systems, Man and Cybernetics, vol. 18, No. 1, pp. 88-104, 1988.

[30] C. Edwards, S. K. Spurgeon and R. J. Patton, "Sliding Mode Observers for Fault Detection 90 and Isolation", Automatica, vol. 36, pp. 541-553, 2000.

[31] C. Edwards and S. Spurgeon, "On the development of discontinuous observers", Int. J. of Control, vol. 59, pp. 1211-1229, 1994.

[32] C. P. Tan and C. Edwards, "An LMI approach for designing sliding mode observers," Int. J. Control, vol. 74, no. 16, pp. 1559-1568, 2001. 
[33] J. Xiang, H. Su and J. Chu, "On the design of walcott-zak sliding mode observer" American Control Conference, pp. 2451-2456, 2005.

[34] C. Edwards and C.P. Tan, "Robust fault detection using slide mode observers", in Advances in Variable Structure and Sliding Mode Control, Springer-Verlag, Berlin, pp.293-312, 2006.

[35] M. H. Khooban, M. Siahi and M. R. Soltanpour. "Model-Based Fault Detection and Estimation in Robotic Wheelchair Using Sliding Mode Observer". Research Journal of Applied Sciences, Engineering and Technology, vol 4, no. 13, pp. 2009-2016, 2012.

[36] Soltanpour MR, Zolfaghari B, Soltani M, Khooban MH. Fuzzy sliding mode control design for a class of nonlinear systems with structured and unstructured uncertainties. International Journal of Innovative Computing, Information and Control. 2013 Jul; 9(7):2713-26.

[37] Heydari-doostabad H, Keypour R, Khalghani MR, Khooban $\mathrm{MH}$. A new approach in MPPT for photovoltaic array based on extremum seeking control under uniform and non-uniform irradiances. Solar Energy. 2013 Aug 31; 94:28-36.

[38] Khooban MH, Alfi A, Abadi DN. Control of a class of non-linear uncertain chaotic systems via an optimal Type-2 fuzzy proportional integral derivative controller. IET Science, Measurement \& Technology. 2013 Jan;7(1):50-8.

[39] Khooban MH, Niknam T. A new intelligent online fuzzy tuning approach for multi-area load frequency control: Self Adaptive Modified Bat Algorithm. International Journal of Electrical Power \& Energy Systems. 2015 Oct 31; 71:254-61.

[40] Niknam T, Khooban MH, Kavousifard A, Soltanpour MR. An optimal type II fuzzy sliding mode control design for a class of nonlinear systems. Nonlinear Dynamics. 2014 Jan 1; 75(1-2):73-83.

[41] Soltanpour MR, Khooban MH. A particle swarm optimization approach for fuzzy sliding mode control for tracking the robot manipulator. Nonlinear Dynamics. 2013 Oct $1 ; 74(1-2): 467-78$.

[42] Khooban MH, Abadi DN, Alfi A, Siahi M. Swarm optimization tuned Mamdani fuzzy controller for diabetes delayed model. Turkish Journal of Electrical Engineering \& Computer Sciences. 2013 Nov 18; 21(Sup. 1):2110-26.

[43] Khooban MH. Design an intelligent proportional-derivative (PD) feedback linearization control for nonholonomic-wheeled mobile robot. Journal of Intelligent \& Fuzzy Systems. 2014 Jan 1; 26(4):1833-43.

[44] Khooban MH, Alfi A, Abadi DN. Teaching-learning-based optimal interval type-2 fuzzy PID controller design: a nonholonomic wheeled mobile robots. Robotica. 2013 Oct 1; 31(07):1059-71.

[45] Kavousi-Fard A, Niknam T, Khooban MH. Intelligent stochastic framework to solve the reconfiguration problem from the reliability view. IET Science, Measurement \& Technology. 2014 Sep; 8(5):245-59.

[46] Soltanpour MR, Khooban MH, Soltani M. Robust fuzzy sliding mode control for tracking the robot manipulator in joint space and in presence of uncertainties. Robotica. 2014 May 1; 32(03):433-46.

[47] Khooban MH, Soltanpour MR. Swarm optimization tuned fuzzy sliding mode control design for a class of nonlinear systems in presence of uncertainties. Journal of Intelligent \& Fuzzy Systems. 2013 Jan 1; 24(2):383-94.

[48] Niknam T, Khooban MH. Fuzzy sliding mode control scheme for a class of non-linear uncertain chaotic systems. IET Science, Measurement \& Technology. 2013 Sep; 7(5):249-55.

[49] Khooban MH, Soltanpour MR, Abadi DN, Esfahani Z. Optimal intelligent control for HVAC systems. Journal of Power Technologies. 2012 Jul 1; 92(3):192.

[50] Khalghani MR, Khooban MH. A novel self-tuning control method based on regulated bi-objective emotional learning controller's structure with TLBO algorithm to control DVR compensator. Applied Soft Computing. 2014 Nov 30; 24:912-22.

[51] Khalghani MR, Shamsi-Nejad MA, Farshad M, Khooban MH. Modifying power quality's indices of load by presenting an adaptive method based on Hebb learning algorithm for controlling DVR. AUTOMATIKA: časopis za automatiku, mjerenje, elektroniku, računarstvo i komunikacije. 2014 Jul 16 ; 55(2):153-61.

[52] Khalghani MR, Shamsi-nejad MA, Khooban MH. Dynamic voltage restorer control using bi-objective optimisation to improve power quality's indices. IET Science, Measurement \& Technology. 2014 Jul; 8(4):203-13.

[53] Khooban MH, Nazari Maryam Abadi D, Alfi A, Siahi M. Optimal Type-2 fuzzy controller for HVAC systems. AUTOMATIKA: časopis za automatiku, mjerenje, elektroniku, računarstvo i komunikacije. 2014 Feb 27; 55(1):69-78.

[54] Alfi A, Kalat AA, Khooban MH. Adaptive fuzzy sliding mode control for synchronization of uncertain non-identical chaotic systems using bacterial foraging optimization. Journal of Intelligent \& Fuzzy Systems. 2014 Jan 1; 26(5):2567-76.

[55] Soltanpour MR, Khooban MH, Khalghani MR. An optimal and intelligent control strategy for a class of nonlinear systems: adaptive fuzzy sliding mode. Journal of Vibration and Control. 2016; 22(1):159-75.

[56] Khooban MH, Niknam T. A new and robust control strategy for a class of nonlinear power systems: Adaptive general type-II fuzzy. Proceedings of the Institution of Mechanical Engineers, Part I: Journal of Systems and Control Engineering. 2015 Mar 24:0959651815571621.

[57] Soltanpour MR, Otadolajam P, Khooban MH. Robust control strategy for electrically driven robot manipulators: adaptive fuzzy sliding mode. IET Science, Measurement \& Technology. 2014 Sep 2; 9(3):322-34.

[58] Ghaemi M, Hosseini-Sani SK, Khooban MH. Direct adaptive general type-2 fuzzy control for a class of uncertain non-linear systems. IET Science, Measurement \& Technology. 2014 Apr 15; 8(6):518-27.

[59] Shahsadeghi M, Khooban MH, Niknam T. A robust and simple optimal type II fuzzy sliding mode control strategy for a class of nonlinear chaotic systems. Journal of Intelligent \& Fuzzy Systems. 2014 Jan 1; 27(4):1849-59.

[60] Abadi DN, Khooban MH. Design of optimal Mamdani-type fuzzy controller for nonholonomic wheeled mobile robots. Journal of King Saud University-Engineering Sciences. 2015 Jan 31; 27(1):92-100. 
[61] Veysi M, Soltanpour MR, Khooban MH. A novel self-adaptive modified bat fuzzy sliding mode control of robot manipulator in presence of uncertainties in task space. Robotica. 2015 Dec 1; 33(10):2045-64.

[62] Shamsi-Nejad M, Khalghani MR, Khooban MH. Determination of optimum hysteresis bandwidth to improve electric machines operation. Journal of Power Technologies. 2013 Jul 1; 93(4):207.

[63] Khooban MH, Niknam T, Sha-Sadeghi M. Speed control of electrical vehicles: a time-varying proportional-integral controller-based type-2 fuzzy logic. IET Science, Measurement \& Technology. 2016 May 1;10(3):185-92.

[64] Abadi DN, Khooban MH, Alfi A, Siahi M. Design of optimal self-regulation Mamdani-type fuzzy inference controller for type I diabetes mellitus. Arabian Journal for Science and Engineering. 2014 Feb 1; 39(2):977-86.

[65] Khalghani MR, Khooban MH, Mahboubi-Moghaddam E, Vafamand N, Goodarzi M. A self-tuning load frequency control strategy for microgrids: Human brain emotional learning. International Journal of Electrical Power \& Energy Systems. 2016 Feb 29;75: 311-9.

[66] Rahimi A, Bavafa F, Aghababaei S, Khooban MH, Naghavi $\mathrm{SV}$. The online parameter identification of chaotic behaviour in permanent magnet synchronous motor by Self-Adaptive Learning Bat-inspired algorithm. International Journal of Electrical Power \& Energy Systems. 2016 Jun 30; 78:285-91.

[67] Khooban MH, Vafamand N, Niknam T. T-S fuzzy model predictive speed control of electrical vehicles. ISA transactions. 2016 May 7.

[68] Dehghani M, Khooban MH, Niknam T. Fast fault detection and classification based on a combination of wavelet singular entropy theory and fuzzy logic in distribution lines in the presence of distributed generations. International Journal of Electrical Power \& Energy Systems. 2016 Jun 30; 78:455-62.

[69] Khooban MH, Naghash-Almasi O, Niknam T, Sha-Sadeghi M. Intelligent robust PI adaptive control strategy for speed control of EV (s). IET Science, Measurement \& Technology. 2016 Feb 29.

[70] Abadi DN, Khooban MH, Siahi M. A novel automated fuzzy model for diabetes mellitus. InControl, Instrumentation and Automation (ICCIA), 2011 2nd International Conference on 2011 Dec 27 (pp. 350-354). IEEE.

[71] Sadeghi MS, Vafamand N, Khooban MH. LMI-based Stability Analysis and Robust Controller Design for a Class of Nonlinear Chaotic Power Systems. Journal of the Franklin Institute. 2016 Jun 2.

[72] Mahboubi-Moghaddam E, Narimani MR, Khooban MH, Azizivahed A. Multi-objective distribution feeder reconfiguration to improve transient stability, and minimize power loss and operation cost using an enhanced evolutionary algorithm at the presence of distributed generations. International Journal of Electrical Power \& Energy Systems. 2016 Mar 31; 76:35-43.

[73] Rafiei M, Niknam T, Khooban MH. Probabilistic electricity price forecasting by improved clonal selection algorithm and wavelet preprocessing. Neural Computing and Applications. 2016:1-3.

[74] Rafiei M, Niknam T, Khooban MH. A novel intelligent strategy for probabilistic electricity price forecasting: Wavelet neural network based modified dolphin optimization algorithm. Journal of Intelligent \& Fuzzy Systems.(Preprint):1-2.

[75] Heydari-doostabad H, Khalghani MR, Khooban MH. A novel control system design to improve LVRT capability of fixed speed wind turbines using STATCOM in presence of voltage fault. International Journal of Electrical Power \& Energy Systems. 2016 May 31; 77: 280-6.

[76] Soltanpour MR, Khooban MH, Niknam T. A robust and new simple control strategy for a class of nonlinear power systems: induction and servomotors. Journal of Vibration and Control. 2016 Apr 1; 22(6):1568-92.

[77] Khooban MH, Niknam T, Blaabjerg F, Dehghani M. Free chattering hybrid sliding mode control for a class of non-linear systems: electric vehicles as a case study. IET Science, Measurement \& Technology. 2016 Oct 1; 10(7):776-85.

[78] Khooban MH, Niknam T, Blaabjerg F, Davari P, Dragicevic T. A robust adaptive load frequency control for micro-grids. ISA transactions. 2016 Jul 28.

[79] Khooban MH, Niknam T, Sha-Sadeghi M. A time-varying general type-II fuzzy sliding mode controller for a class of nonlinear power systems. Journal of Intelligent \& Fuzzy Systems. 2016 Jan 1(Preprint):1-1.

[80] Bavafa F, Rahimi A, Khooban MH. A simple and intelligent online parameter identification of nonlinear chaotic systems. Journal of Intelligent \& Fuzzy Systems. 2015 Oct 23;29(4):1501-9.

[81] Khooban MH, Sha-Sadeghi M, Niknam T, Blaabjerg F. Analysis, Control and Design of Speed Control of Electric Vehicles Delayed Model: Multi-Objective Fuzzy Fractional-Order PI $\lambda \mathrm{D} \mu$ Controller. IET Science, Measurement \& Technology. 2016 Nov 18.

[82] Khooban MH, Niknam T, Blaabjerg F, Dragičević T. A new load frequency control strategy for micro-grids with considering electrical vehicles. Electric Power Systems Research. 2016 Nov 9.

[83] Khooban MH, Vafamand N, Liaghat A, Dragicevic T. An optimal general type-2 fuzzy controller for urban traffic network. ISA transactions. 2016 Nov 3.

[84] Khooban MH, Vafamand N, Dragicevic T, Blaabjerg F, Niknam T. Model Predictive Control based on TS Fuzzy model For Electrical Vehicles Delayed Model. IET Electric Power Applications. 2016 Oct 27.

[85] Naghavi SV, Naghavi SV, Safavi AA, Safavi AA, Khooban MH, Khooban MH, Pourdehi S, Pourdehi S, Ghaffari V, Ghaffari V. A robust control strategy for a class of distributed network with transmission delays: LMI-based model predictive controller. COMPEL-The international journal for computation and mathematics in electrical and electronic engineering. 2016 Sep 5; 35(5):1786-813.

[86] Azami A, Naghavi SV, Tehrani RD, Khooban MH, Shabaninia F. State estimation strategy for fractional order systems with noises and multiple time delayed measurements. IET Science, Measurement \& Technology. 2016 Aug 19.

[87] Naghash-Almasi O, Khooban MH. PI adaptive LS-SVR control scheme with disturbance rejection for a class of uncertain nonlinear systems. Engineering Applications of Artificial Intelligence. 2016 Jun 30; 52:135-44. 
[88] Modirkhazeni A, Almasi ON, Khooban MH. Improved frequency dynamic in isolated hybrid power system using an intelligent method. International Journal of Electrical Power \& Energy Systems. 2016 Jun 30; 78:225-38.

[89] Khooban MH, Siahi M, Soltanpour MR. Robust and simple intelligent observer-based fault estimation and reconstruction for a class of non-linear systems: HIRM aircraft. The Aeronautical Journal. 2016 Mar 1; 120(1225):457-72.
[90] Dehghani M, Khooban MH, Niknam T, Rafiei SM. Time-Varying Sliding Mode Control Strategy for Multibus Low-Voltage Microgrids with Parallel Connected Renewable Power Sources in Islanding Mode. Journal of Energy Engineering. 2016 Feb 29:05016002.

[91] Nayeripour M, Mahboubi-Moghaddam E, Khooban MH. Multi-periods distribution feeder reconfiguration at the presence of distributed generation through economic assessment using a new modified PSO algorithm. Journal of Intelligent \& Fuzzy Systems. (Preprint):1-1. 